\title{
Cultura Cultura
}

\section{Circulação, apropriação e actualidade das ideias contra a Guerra Colonial}

Notas críticas de problematização

\section{Daniel Melo}

\section{(2) OpenEdition}

\section{Journals}

Edição electrónica

URL: http://journals.openedition.org/cultura/2470

DOI: 10.4000 /cultura.2470

ISSN: 2183-2021

\section{Editora}

Centro de História da Cultura

\section{Edição impressa}

Data de publição: 9 Junho 2015

Paginação: 249-290

ISSN: 0870-4546

\section{Refêrencia eletrónica}

Daniel Melo, «Circulação, apropriação e actualidade das ideias contra a Guerra Colonial », Cultura [Online], Vol. 34 | 2015, posto online no dia 08 julho 2016, consultado a 20 abril 2019. URL : http:// journals.openedition.org/cultura/2470; DOI : 10.4000/cultura.2470

Este documento foi criado de forma automática no dia 20 Abril 2019.

(c) CHAM - Centro de Humanidades / Centre for the Humanities 


\title{
Circulação, apropriação e actualidade das ideias contra a Guerra Colonial
}

Notas críticas de problematização

\author{
Daniel Melo
}

1 O presente texto pretende ser um contributo para o estudo da apropriação, circulação e actualidade crítica das ideias e posicionamentos contra a guerra, tomando a Guerra Colonial portuguesa como vector central e dialogando criticamente com outros elementos de um dossiê temático, incluindo transcrição de documentos da época e de testemunhos inéditos. Este dossiê parte de um encontro temático que desde Junho de 2015 tem procedido à recolha de testemunhos de cidadãos comuns cujo percurso biográfico foi marcado por esse trauma social, os quais reflectem sobre a sua apropriação de autores e obras que os influenciaram.

2 A organização desse encontro e a reflexão daí decorrente que estimula a presente análise crítica têm três objectivos principais: colmatar uma lacuna na reflexão sobre a Guerra Colonial e a memória pública; criar e disseminar novas fontes históricas temáticas a partir de testemunhos orais; e aprofundar um território de pesquisa para os estudos póscoloniais, sobre a memória histórica e de grupo, e sobre o impresso e a leitura.

\section{Problematização e enquadramento crítico de um encontro temático inovador}

3 O encontro em apreço, intitulado "Um livro, uma revista, uma canção contra a Guerra Colonial", procura recolher testemunhos de pessoas que assumiram uma postura crítica face à Guerra Colonial que decorreu em parte do Império português entre 1961 e 1974, postura essa potenciada pela apropriação e disseminação de conteúdos culturais marcantes durante esse período. $O$ tema da Guerra Colonial é tanto mais premente quanto tem merecido redobrada atenção da academia, mas permaneceu silenciado durante largo 
tempo, no espaço público mas também na expressão pública, por parte dos envolvidos nesse confronto bélico, fossem os militares fossem os desertores, refractários e exilados em geral. ${ }^{1}$

Aos oradores é proposto um formato assente em três bens/suportes culturais concretos: $\mathrm{o}$ livro, pelo seu prestígio, presença relevante com capacidade de sistematizar e expandir o pensamento mais reflexivo; a revista, por ser um meio usado na intervenção dos intelectuais, nesse tempo com um pendor ainda mais ensaístico, teórico, politizado e ligado às ciências sociais e humanas; a canção, por circular num suporte, o disco de vinil, que se tornou então um objecto mais vulgarizado e difundido (incluso na telefonia e via trocas interpessoais frequentes), com cunho mais actual e interventivo do que em épocas precedentes.

5 O critério seguido deixou de lado diversos outros suportes então em voga: os espectáculos (em especial, o filme no cinema/cineclube), o folheto volante, o cartaz e o jornal. Esta delimitação deveu-se a razões logísticas e de legibilidade do título do encontro, bem como ao interesse do organizador em centrar o encontro no tipo de fontes mais estudadas no centro de investigação que tem dado suporte institucional à iniciativa e do qual faz parte, que é o CHAM.

6 Assim, a escolha pessoal de cada convidado consubstancia-se primeiramente num depoimento oral feito em sessão pública (ou lido por outrem, caso não possa estar presente), acompanhado pela divulgação de imagens e breves notas (em projecção ou impressas) e pela audição da canção eleita (complementada por uma versão em português, no caso de ser em língua estrangeira, o que tem ocorrido). Segue-se um período de debate, que se pretende vivo, aberto e convidando à interpelação por parte do público, o qual foi previamente convidado através de materiais de divulgação (vd. anexos).

7 Retomando os grandes objectivos do encontro e deste dossiê, importa realçar que eles se entrecruzam. Por um lado, o desafio da apresentação de testemunhos ligados à consciencialização cívica no quadro da Guerra Colonial portuguesa (e das outras guerras hodiernas) visa não só a criação de um acervo temático de fontes primárias inéditas mas também a salvaguarda da memória de grupo e a historicização das práticas de memória sobre um fenómeno traumático e fortemente marcante da História de Portugal, cujas interacções tiveram relevância na diáspora portuguesa e na História do mundo, no contexto mais lato da descolonização contemporânea e da sua inter-relação com a Guerra Fria. ${ }^{2}$ Nesse sentido, uma das inovações que se busca é a de dar voz a grupos de exilados cujo legado foi abafado pela censura política da ditadura salazarista e marcelista, pela distância geográfica, pelo olvido e pelo perfil de memória pública que se afirmou em Portugal no decurso dos 40 anos que nos separam do fim dessa guerra. Por outro lado, esse propósito é explorado a partir do desafio duma escolha pessoal de conteúdos difundidos através de bens culturais delimitados: o livro, a revista e a canção.

Pretende-se assim contribuir para um conhecimento mais aprofundado dos tempos e modos de circulação de conteúdos culturais que alimentaram o ideário progressista e a resistência. Uma resistência que se construíra a nível mundial: contra as outras guerras que então ecoavam (da Guerra Fria ao Vietname e a Cuba), contra a opressão colonialista e as ditaduras. Buscou-se desse modo romper com fronteiras criadas em nome da nação: os nacionalismos belicistas, o colonizador vs. o colonizado. 
Esta perspectiva abre espaço a um novo campo de pesquisa para os estudos sobre o impresso e a leitura e para os estudos pós-coloniais, em torno da apropriação e circulação de bens culturais ligados ao impresso e que tiveram usos muito concretos: a reflexão multímoda (ainda que partindo da temática da guerra e do colonialismo para abordar as relações interétnicas, as diferentes perspectivas de democracia, da autonomia do indivíduo e da construção partilhada da sociedade); o debate no espaço público e semipúblico (e o lugar dos circuitos clandestinos ou subversivos nesse quadro); a aproximação entre indivíduos para além dos laços mais tradicionais (v.g., o associativismo formal, a sociabilidade religiosa); o papel da crítica na criação duma visão do mundo; tudo isso favorecendo a consciencialização cívica e, depois, a criação duma postura de intervenção político-ideológica e político-cultural, que desemboca numa certa identidade de resistência e contestação, tudo isso sendo relevante analisar e compreender no contexto dos estudos sobre as memórias pública, histórica e de grupo.

Numa primeira fase optou-se por articular o formato da apresentação oral com o convite para a passagem a escrito do essencial dos depoimentos e sua inclusão em dossiê de revista académica. Esta opção justifica-se por valorizar um diálogo entre depoente e investigador, entre depoente e públicos diversos (o presencial e o potencial leitor da revista académica), por valorizar conteúdos complementares, ao permitir introduzir um enquadramento crítico problematizante feito pelo organizador do encontro. Esta opção fez-se em detrimento da recolha áudio ou audiovisual dos depoimentos, dados os constrangimentos previsíveis a nível pessoal, a ainda pouca familiaridade existente no nosso país quanto a uma tradição de recolha de fontes orais e de preservação de registos da História oral. Não obstante, fica salvaguardado que o essencial do encontro possa ser do conhecimento dum auditório mais alargado, deste modo possibilitando uma reflexão mais diversificada e distendida no tempo, bem como o confronto e diálogo entre os vários depoimentos.

O dossiê que este artigo integra pretende dar a conhecer o conteúdo das duas primeiras sessões, que decorreram na Biblioteca Municipal Camões, instituição que já tinha acolhido uma iniciativa do autor no âmbito do debate sobre o património dos agentes do livro, contando ainda com o apoio da Câmara Municipal de Lisboa ao nível da divulgação, o que se aproveita para agradecer publicamente.

\section{Da Angola e da Argélia tardo-coloniais ao "Terceiro Mundo": a Imbondeiro e afins; a teoria anticolonial de Albert Memmi; a revista Croissance des jeunes nations; as canções de Chico Buarque}

12 A sessão inaugural, que serviu de ensaio, integrou dois depoimentos, de Leonel Cosme e de António Melo, e decorreu a 17 de Junho de 2015.

13 O testemunho de Leonel Cosme foi lido pelo organizador, uma vez que o autor não pôde estar presente por motivos de saúde (vd. anexos). 0 texto em apreço não chegou a seguir o formato de "um livro, uma revista, uma canção", pois julgou-se mais interessante solicitar um depoimento abrangente, sobre os contextos do pensar a Guerra Colonial na Angola tardo-colonial em que Leonel Cosme interveio, enquanto jornalista, animador cultural, escritor, livreiro, distribuidor e editor. 
família. Viveu durante 30 anos na cidade de Sá da Bandeira (actual Lubango), tendo aí trabalhado na Rádio Clube de Huíla e na imprensa. Foi ainda co-fundador do Cineclube da Huíla e da livraria-distribuidora Imbondeiro. Esta livraria-distribuidora, criada em 1960, foi usada para fazer passar a edição própria nas áreas da poesia e do conto, começando na inaugural "Colecção Imbondeiro", fórmula encapotada duma verdadeira editora, ${ }^{3}$ que publicou nomes relevantes duma certa angolanidade emancipadora (a nível político e/ ou cultural, casos de Agostinho Neto e José Luandino Vieira), entre diversos escritores do Brasil, Cabo Verde, Portugal metropolitano e da literatura universal, esta já inserida noutra colecção da mesma empresa. A sua produção foi distribuída por todo o território nacional e pelo Brasil, e chegou a alcançar dois mil exemplares por tiragem (Cosme, 2004: 141-66 e 2015).

15 A relevância da livraria-distribuidora-editora Imbondeiro foi de tal monta que levou ao seu fecho, após as apreensões pela polícia política do caderno n.․ 69 da Colecção Imbondeiro (com texto do guerrilheiro independentista Luandino Vieira), na Gráfica da Huíla, e de toda a documentação existente nos escritórios daquela sociedade, apreensões estas efectuadas em Dezembro de $1964 .^{4}$

Cosme foi ainda o autor de um conto sobre a Guerra Colonial, os mortos inúteis, publicado como livro n. 3 da "Colecção Círculo", que funcionava como biombo da editora dirigida por Garibaldino de Andrade (outro dos co-fundadores da Imbondeiro), e que foi apreendido pela PIDE em 1967, levando ao fim deste projecto, com apenas dois meses de existência (Cosme, 2004: 195).

17 Regressou à antiga metrópole de modo definitivo em 1987, tendo trabalhado como jornalista no Porto e em Lisboa. A partir de 1990 passou a dedicar-se inteiramente à actividade literária e ensaística, tendo escrito uma pentalogia genericamente intitulada $A$ revolta (1963-2009) e estudos sobre a literatura angolana, como Cultura e revolução em Angola (1978) e Agostinho Neto, a poesia e o homem (1984). ${ }^{5}$

18 No depoimento que nos deixou, "A literatura e as guerras em Angola. No princípio era o Verbo", Leonel Cosme faz uma digressão pela resistência e a apropriação da palavra nos vários pronunciamentos identitários (entre a africanidade, a angolanidade e a portugalidade) que decorreram de 1575 a 1974 no território que veio a ser Angola.

19 O testemunho seguinte desta sessão inaugural foi de António Melo, que escolheu o livro Retrato do colonizado precedido do retrato do colonizador, de Albert Memmi, a revista Croissance des jeunes nations e duas canções de Chico Buarque do mesmo ano de 1966.

António Melo pertenceu à geração da crise académica de 1962 em Lisboa, que resistiu à ofensiva ditatorial contra a autonomia universitária, e as suas escolhas foram marcadas pelas leituras dessa geração universitária, pela vivência nos espaços da Juventude Universitária Católica (JUC), dos católicos progressistas e da contestação estudantil frentista, num primeiro momento (e daí vem a escolha da revista Croissance des jeunes nations, para estes activistas da JUC um prolongamento livre do seu jornal Encontro), e dos marxistas e outros anticolonialistas, num segundo momento. ${ }^{6}$

21 A sua expulsão da universidade, junto com a consciencialização política e cívica que aí desenvolvera quanto à aberração da Guerra Colonial, levaram-no a desertar do alistamento militar compulsivo, a fugir clandestinamente do país e a exilar-se em Bruxelas, cidade onde viveu entre 1967 e 1974. Completou os seus estudos universitários na Université Libre de Bruxelles, na condição de trabalhador-estudante e com o estatuto 
de refugiado da $\mathrm{ONU}$, tendo integrado um meio estudantil agitado em torno da questão da Guerra do Vietname e do Maio de 1968. Integrou ainda a pequena mas activa comunidade internacional de exilados políticos que então aí se formou, com foragidos das várias ditaduras ibero-americanas, especialmente de Portugal e do Brasil. Era uma comunidade culta, muito politizada e muito envolvida no debate de ideias, como atestam várias fontes recentes. ${ }^{7}$ Depois da revolução de 1974 regressou a Portugal, onde fez o serviço militar e realizou uma intensa actividade jornalística. Nessa actividade produziu diversos textos sobre a resistência anti-salazarista, tendo reunido parte do material de entrevistas em livro (vd. Melo \& Carmo, 2001).

22 A leitura do mais conhecido livro de Albert Memmi foi muito marcante para si, de tal modo que se convenceu de o ter lido muito cedo, ainda antes de desertar, e numa edição portuguesa que ainda nem sequer existia, a qual só sairia em 1974, curiosamente pela mão dum seu conhecido do exílio belga, "o saudoso João Paisana, outro que também viveu em Bruxelas, para os lados da Porte de Namur", como confidencia no seu testemunho. ${ }^{8} \mathrm{Em} e$ mail pessoal para os seus amigos aditou uma nota relevante: "É possível que o Retrato do colonizado precedido do retrato do colonizador tenha chegado ao conhecimento de alguns em Portugal quando foi pela primeira vez editado em Paris, em 1957. Mas, em termos de divulgação, mesmo se clandestina, só em 1966 ele por cá chegou - e foi um choque."

Esta nota merece destaque por evidenciar a pluralidade e o modo de circulação de várias versões de livros perseguidos e por mostrar como a estigmatização oficial podia provocar atraso na sua recepção pelo público, o que não foi regra geral, como veremos adiante com o caso do livro escolhido por José Rosa. É também útil porque revela o impacto que a leitura de um livro podia ter, provocando uma forte reacção emocional e mental, e causando um marco no percurso biográfico do leitor. Esse impacto deveu-se ao facto de este livro lhe ter permitido perceber dum modo inteligível e fundamentado o que era o colonialismo. $\mathrm{O}$ que não podia ser coisa pouca, para alguém ainda jovem que de repente se via defronte duma guerra que essa mesma engrenagem provocara no país em que vivia e que implicava toda a sociedade portuguesa, mas pedindo em especial a hipoteca dos destinos dos mais jovens. Ainda que falando do colonialismo francês e ecoando uma guerra distante, a da Argélia, Memmi teve o dom de elaborar um discurso interpretativo que, no olhar de António Melo, e decerto de muitos da "sua geração" (a atestar pelo sentido do debate), revelava o que era comum aos vários colonialismos, o seu cunho opressivo, feito de relações assimétricas e ambivalentes, de mútua dependência e destrutivo das identidades individuais e colectivas mais amplas.

Retomo a questão da circulação dos textos para referir que este, em particular, mostra a plasticidade que alguns conteúdos podiam ter, pois circularam previamente versões exploratórias lidas em público e publicadas em jornais e revistas, só depois sendo incorporadas em livro. ${ }^{9}$ A maior visibilidade deste texto deve-se em parte ao paratexto de Jean-Paul Sartre, uma recensão crítica que o mesmo publicara ao primeiro dos textos de Memmi num n.. posterior da revista Les Temps modernes (o n.. 137-138, de Julho-Agosto de 1957), revista essa que era dirigida por este pensador. Ora, Sartre era então o grande porta-voz da contestação à Guerra da Argélia (o que lhe valia a hostilidade do regime e da direita nacionalista francesa) e uma estrela em ascensão do pensamento crítico contemporâneo, sendo na década seguinte o intelectual público mais influente na esfera pública francesa (e não só). ${ }^{10}$ Esse paratexto foi depois incorporado em livro na forma de prefácio, e reproduzido em todas (ou quase todas) as futuras versões, dessa ou doutras editoras, nacionais ou estrangeiras. ${ }^{11}$ 

colonialismo numa perspectiva diacrónica bem como a consideração da inevitabilidade do fim do(s) colonialismo(s), o que na altura parecia bem mais distante para contextos como o português. Essa abordagem sustentou-se na análise da dialéctica entre colonizado e colonizador, que Memmi distanciava do idealismo hegeliano e aproximava de Racine, apesar de a dialéctica mestre-escravo ser uma abordagem mais recente e conhecida (dialéctica donde partiria o próprio materialismo dialéctico, marxista, ainda que numa reinterpretação crítica radical). colonialismo, foi em si mesma um contributo relevante de Memmi para a formação dum pensamento teórico da descolonização. Outro contributo central foi a capacidade que teve para, na sua abordagem, conciliar as experiências particulares de cada país africano em luta pela independência com uma noção de universalismo que unificasse essas mesmas experiências - à cabeça, com a denúncia da iniquidade do colonialismo (centrado no privilégio, no racismo, na exploração por uma minoria face a uma maioria) -, reforçando a sua legitimidade política e dando-lhes um sentido de partilha, um internacionalismo com implicações internas e geopolíticas (Crowley, 2012; Dugas, 2011), mas salvaguardando o carácter nacional das guerras de descolonização (Sanson, 2014: 6). Esta dimensão estava em sintonia com a compreensão da problemática nacional (ou do Estado-nação) de cada país emergente dum modo integral, ou seja, importava ver o novo país pós-colonial numa perspectiva global e integrado num quadro regional (no caso da Tunísia, por exemplo, seria o quadro norte-africano) e não apenas na sua dimensão económica ou outra. Um derradeiro aspecto relevante foi a denúncia do sofrimento e dos abusos infligidos dum modo sistemático pelo colonialismo, ligando a experiência colectiva - em boa medida marcada pelo racismo, pelo sentimento de superioridade racial e etnocultural, com implicações transversais na sociedade - à revelação de experiências individuais de cunho traumático, dimensão facilitada pela sua abordagem psicocultural e psicossocial e pela sua experiência enquanto director num centro psicopedagógico em Túnis (Vainfas, 2008; Dugas, 2011; Crowley, 2012).

e-se que Retrato do colonizado precedido do retrato do colonizador é um livro que teve uma difusão significativa, a atestar pela diversidade de apropriações políticas ${ }^{12}$ e teóricas ${ }^{13}$ e pelo número de edições pretéritas, ${ }^{14} \mathrm{e}$ que foi recentemente recuperado, tanto na academia (v.g.., Vainfas, 2008; Dugas, 2011; Crowley, 2012; Muzzio, 2013; Sanson, 2014) como na edição: Gallimard (Paris, 2002), Earthscan (Londres, 2003), ${ }^{15}$ Éditions ANEP (Argel, 2006, col. "Voix de l'anticolonialisme"), Civilização Brasileira (Rio de Janeiro, 2007), Routledge (Londres, 2013, v. revista).

Memmi voltou ao tema, agora para aferir o que resultara das independências coloniais, tendo publicado Retrato do descolonizado árabe-muçulmano e de alguns outros, em 2004 (v. port. por Civilização Brasileira, Rio de Janeiro, 2007). Neste livro avalia a condição do descolonizado nas ex-colónias e nas ex-metrópoles, nestas enquanto imigrante. É uma obra carregada de desilusão perante a persistência da opressão, da corrupção e das desigualdades mais gritantes, e nisso não se afasta da visão de muitos outros intelectuais da sua geração quanto aos efeitos das independências e, sobretudo, dos regimes políticos que lhes sobrevieram. Onde talvez ainda se distinga é na denúncia dos desajustes identitários, agora centrados no uso pseudolibertário do véu por parte da mulher árabemuçulmana, na hiperocidentalização dos mais jovens, etc.

Cultura, Vol. 34 | 2015 

referir não só o seu enquadramento progressista e crítico como o seu envolvimento programático com as sociedades dos países então ditos subdesenvolvidos do chamado "Terceiro Mundo" (aquele que estava fora da órbitra dos mundos capitalista e comunista), numa perspectiva de desenvolvimento e emancipação dos povos desses vastos territórios, sintonizada com a abertura proporcionada pelo Concílio Vaticano II, a qual viria a ter como epígono mais radical a "teologia da libertação". Nessa altura, entre os fenómenos sociais mais criticados pela Santa Sé estavam o racismo, a guerra, a pobreza e a violência política exercida pelas ditaduras, reforçando o argumentário contra as guerras coloniais (e outras) então em curso. A postura anticolonial da revista fundada pelo activista católico Georges Hourdin tinha expressão no próprio título da publicação, pois as "jeunes nations" a que alude eram as jovens nações saídas da descolonização. A abordagem centrada na emergência e estudo dos problemas do "Terceiro Mundo" irá ser uma das fontes da corrente internacional do diálogo Norte-Sul. Cabe aqui mencionar a existência duma ligação directa entre Memmi e a revista, na forma duma entrevista (vd. Memmi, 1965).

A canção "Funeral de um lavrador" (do álbum Morte e vida severina), musicada por Chico Buarque em 1966 sob texto de João Cabral de Melo Neto, tornou-se uma escolha plena de simbolismo, por várias razões: por ser da autoria dum músico também ele um exilado e que ecoou momentos marcantes do diálogo entre Portugal e Brasil no século XX em várias das suas canções (v.g., "Fado tropical" e "Meu caro amigo"); por ser um texto que denuncia a opressão quase intemporal dos desfavorecidos, extensivo à condição colonial (vd. anexos); e por reenviar para a representação da peça teatral homónima em Lisboa, evento de última hora que não foi censurado e que foi presenciado por António Melo. 0 mesmo apresentou como alternativa uma outra canção de Chico Buarque, "A banda" (do álbum Chico Buarque de Hollanda, também de 1966), uma canção de amor cuja escolha se justificaria simplesmente por ser uma canção de amor: o amor seria então o melhor antídoto contra a guerra. Esta perspectiva abre portas para um entendimento mais abrangente da postura antibelicista.

Resta referir que o texto que António Melo nos entregou para publicação, intitulado "À toa na vida até chegar o tempo de ler, ouvir e ver - não podemos ignorar", espelha fielmente o que foi o seu testemunho na sessão, só lhe escapando os vivos diálogos travados no período de debate.

\section{A teoria anticolonial de Frantz Fanon; a contestação à guerra pela revista Hara-Kiri e por Vian \& Reggiani e a sua censura}

32 A segunda sessão da tertúlia decorreu a 14 de Outubro de 2015, também na Biblioteca Municipal Camões, e integrou o depoimento de José Rosa, que escolheu um livro de Frantz Fanon, a revista Hara-Kiri e a canção "Le déserteur".

José Rosa, presentemente reformado, foi um desertor com armas em 1967 e antigo exilado em Bruxelas entre 1967 e 1974. Em Bruxelas e Paris colaborou nalgumas iniciativas duma conhecida organização de luta armada anti-salazarista, a LUAR - Liga de Unidade e Aç̧ão Revolucionária. Após o seu regresso a Portugal, foi um dos guarda-costas do então primeiro-ministro Vasco Gonçalves na fase do PREC (Período Revolucionário em Curso), e 
depois desenvolveu a sua actividade na área dos recursos humanos, para o que contribuiu a sua experiência profissional na Societé Générale de Belgique, em Bruxelas.

A nova escolha principal recaiu num livro póstumo de Frantz Fanon, Os condenados da terra , lido na versão portuguesa lançada pela Ulisseia no mesmo ano da sua edição original em francês (Les Damnés de la terre, Paris, Éds. Maspero), ou seja, em 1961, por iniciativa do seu novel director literário Vítor Silva Tavares..$^{16}$ Esse foi o ano do início da Guerra Colonial e o livro passou então incólume pelo crivo censório, o que só pode ter uma justificação: as boas relações existentes entre o empresário dono da editora Ulisseia, Joaquim Figueiredo Magalhães, e alguns censores. ${ }^{17}$ Mas em 1965 o livro seria apreendido e "proibido de circular" no país, após denúncia dos serviços de censura em Angola de que era "um livro violento, onde os crimes do preto são justificados e um incentivo à revolta", com uma agravante: "Livros como este circulam entre toda a camada estudantil e intelectual na Metrópole e agora andam por aqui, trazidos por muitos destes jovens convocados para o Serviço Militar". ${ }^{18} \mathrm{O}$ exemplar lido por José Rosa fora adquirido pelo seu irmão numa livraria de Lisboa. Foi uma leitura marcante, a partir da qual assumiu a sua opção contra a Guerra Colonial. Daí que, tendo recebido ordem de alistamento em 1965, tenha desertado pouco depois, em 1967, abandonando o seu posto de recruta no Regimento de Infantaria n.. 2 (Abrantes) e levando algumas armas do depósito, junto com o aspirante miliciano Carlos Pinto dos Santos.

Esta leitura foi feita em paralelo a outras afins, de livros trazidos pelo irmão mais velho, engenheiro de profissão, das suas viagens ao Brasil. Entre essas obras figurava o livro de crítica anti-imperialista A Verdadeira História do Tio Sam, escrito pelo ensaísta argentino Ezequiel Martinez Estrada e ilustrado pelo cartoonista francês Maurice Siné (São Paulo, Editora Fulgor, 1963; v. or. esp. El verdadero cuento del Tío Sam, Havana, Casa de las Américas, 1962).

O ensaio póstumo de Frantz Fanon representa uma excelente sequência com Memmi, pois ambos reflectem sobre a relação colonizador-colonizado nessas suas obras de referência. O texto que Fanon escreveu nos últimos meses duma vida breve realça igualmente o efeito destruidor do colonialismo sobre as identidades individuais e colectivas, a começar no próprio autor, que, como realçou José Rosa, se apercebeu dos sucessivos estigmas sociais que se lhe colaram à pele consoante o espaço social em que se foi movendo: na sua ilha natal, Martinica, era um colonizado, mesmo tendo pertencido à Resistência francesa; na França metropolitana era um preto; e na Argélia colonial, para onde decidiu ir viver, situava-se numa terra de ninguém, pois também não era árabe, embora tenha aderido à causa independentista. As fronteiras sociais eram assim mais complexas, estando para além da desocultação da relação colonizador-colonizado, embora essas mesmas fronteiras fossem fortemente exacerbadas pelo fenómeno colonial. Fanon aproveitou-se da sua experiência enquanto psiquiatra na Argélia e na Tunísia tardo-colonial para aprofundar a análise psicológica dos efeitos do colonialismo que Memmi já tinha iniciado. Nesse sentido, o livro tem uma parte dedicada à exposição dos traumas provocados pelo racismo colonial, pela guerra, pela tortura e outras sevícias exercidas sobre pacientes seus ou sobre parentes e outras pessoas próximas.

Mas Fanon vai mais longe do que Memmi ao pretender oferecer um guia para a libertação do jugo colonial - e aqui se condensa um dos seus principais contributos para a formação do pensamento teórico da descolonização -, seja para o despertar das consciências, seja na luta armada e política: considera que a extinção do colonialismo implicará necessariamente o uso da violência, pois aquele edifica-se no exercício brutal da violência 
a todos os níveis. Um novo uso da violência serviria para a criação dum "novo homem", duma "nova humanidade", só podendo ser exercida de modo eficaz pelo envolvimento massivo dos mais despossuídos e, portanto, pelos menos alienados pela lógica colonial, ou seja, o proletariado rural. A obra tem portanto uma dimensão instrumental, mas não se esgota aí. Ao contrário de muitos, incluindo Memmi, Fanon manteve uma lucidez crítica quanto ao pós-independência do jugo colonial, alertando em vários momentos do livro para que a construção duma nova sociedade seria tarefa demorada, árdua e incerta, podendo as novas nações reincidir na opressão político-social e económica se não se libertassem dos interesses egoístas das elites locais e da lógica capitalista em geral. Cada país devia seguir o seu próprio ritmo, recusar o modelo decadentista europeu (que criara o colonialismo e retirara as riquezas naturais às ex-colónias) e seguir o modelo socialista, o qual só vingaria se fosse um fenómeno internacional, que permitisse romper com os laços de dependência económica que o capitalismo fora instituindo ao longo de séculos. É neste quadro que Frantz Fanon é tido como um dos fundadores do pensamento terceiromundista, estando assim ao lado da revista Croissance des jeunes nations, o que lança uma nova ponte com a sessão anterior. Fanon preconizava que cada cultura nacional, para ser viva e autêntica, tinha de se actualizar constantemente, em linha com as necessidades e aspirações de cada povo e só aceitando a tradição enquanto possibilidade de reinterpretação criativa. A perspectiva da "negritude", de que fora em tempos um defensor enquanto cúmplice de Aimé Césaire, era agora apresentada como desajustada do tempo hodierno, por achar que se tornara uma mera emulação, por parte duma elite cultural colonizada ou ex-colonizada, dum modelo de cultura tipicamente ocidental (não necessariamente baseado na cultura erudita, o jazz ele próprio tinha-se perdido ao fixarse no imobilismo do bebop). Esta crítica, que lhe valeu algum ostracismo e contestação por teóricos próximos, era extensiva à análise do lugar do intelectual na sociedade, que Fanon considerava uma categoria de privilegiado por agir como mero reprodutor do modelo cultural ocidental. Tal como o livro de Memmi, também este teve um prefácio de Sartre, o que também terá ajudado à sua visibilidade e, em certo sentido, aumentado a polémica, pois o influente intelectual público francês insistiu na questão controversa do uso da violência política, entre outros aspectos realçados por José Rosa. Tal como com Memmi, também Fanon está a ser alvo duma reavaliação pública, com apropriações diversas pela academia ${ }^{19}$ e novas edições de Os condenados da terra em vários países: em França (La Découverte, 1985 e 2002; Gallimard, 1991), em Portugal (Ulmeiro, 198?; Letra Livre, 2015), no Reino Unido (Penguin Books, 2001), na Suíça (Genebra, Éditions du CETIM, 2013), no Brasil (Juiz de Fora-Minas Gerais, UFJF, 2. ${ }^{a}$ reimpr. actualizada, 2013).

Quanto à revista, a escolha de José Rosa recaiu num periódico marcante do espaço francófono dos anos 1960-70, a Hara-Kiri (Paris, Éditions du Square, 1960-86). Esta publicação, fundada pela dupla François Cavanna e Georges Bernier/Prof. Choron, começou por ser uma reactualização dos antigos folhetos populares de crítica social e política, a que os franceses davam o nome de canards. ${ }^{20}$ Mas o seu ímpeto iconoclasta e subversivo era maior, muito graças ao forte apelo visual contido nas inúmeras provocações fotográficas e na contundência e criatividade duma plêiade de novos cartoonistas, denunciando os vários abusos de poder, incluindo a guerra e a violência policial, e expondo os vários interditos, desde o papel do sexo à hipocrisia e alienação religiosa e moral. Chegou a tirar mais de duzentos mil exemplares. O seu efeito no espaço público foi tal que foi encerrada várias vezes pelo governo francês, alegadamente por ser "perigosa para a juventude" (em 1961), por ser "pornográfica" (1970), etc., e interdita no espaço militar nos anos 1970 (tal como o jornal comunista L'Humanité). ${ }^{21}$ Para melhor se 
sustentar em termos editoriais e financeiros, em 1969 criou uma versão semanal, intitulada Hara-Kiri Hebdo/ L'Hebdo Hara-Kiri, a qual seria a antecessora da Charlie Hebdo, um periódico surgido após o fecho de 1970 e recentemente alvo da repressão doutros poderes, o do terrorismo fundamentalista islâmico.

Quanto à canção, a opção por "Le Déserteur", numa interpretação de Serge Reggiani (de 1964), deveu-se necessariamente à condição de desertor de José Rosa. A parte principal desta canção foi escrita por Boris Vian em 1954. Sucede que a versão original terminava num verso que era um desafio directo à autoridade, numa assunção da deserção enquanto reacção armada. Tal verso foi depois alterado para uma deserção enquanto reacção passiva, devido à polémica gerada. Contudo, mesmo esta versão foi alvo de perseguição, que atingiu Serge Reggiani. Na versão deste cantautor francês, a letra de Vian era precedida dum poema de Rimbaud, "Le dormeur du val" (1870), uma espécie de écloga bucólica a um soldado desconhecido e inocente, em contraste com a restante letra (vd. anexos). Apesar da perseguição, a canção de Boris Vian teve inúmeras interpretações, um pouco por todo o mundo. ${ }^{22}$

\section{Breves notas finais}

Embora tendo origens geográficas e meios sociais e formativos distintos, os oradores cujos testemunhos foram aqui enquadrados e analisados criticamente acabam por estabelecer diversos pontos de contacto.

41 Em primeiro lugar, na sua determinação e coragem para romperem com uma ordem ditatorial estabelecida, questionarem o colonialismo e recusarem a Guerra Colonial, apesar da ruptura biográfica que isso implicava e dos custos pessoais envolvidos. Trata-se de distintos tipos de ruptura que são partilhados: ruptura intelectual e cívica, ruptura militar (deserção), esta não partilhada pelos três mas por todos aceite como legítima.

42 Em segundo lugar, as leituras de livros e revistas (ou o envolvimento com o escrito, em termos mais gerais) são marcantes para eles, levando não só a legitimar opções de vida como a cimentar os seus percursos cívicos e/ou profissionais e a alimentar as suas sociabilidades quotidianas.

Em terceiro lugar, as próprias obras escolhidas têm autores de contacto (prefácios de Sartre para as obras de Memmi e Fanon) ou os mesmos contextos intelectuais: a literatura e o ensaio comprometidos; a França como espaço de referência intelectual, seja no uso político-cívico da literatura, seja nalguns dos autores eleitos; etc.

Em quarto lugar, vislumbra-se uma certa heterodoxia no tipo de leituras propostas. Assim, e retomando Memmi e Fanon, estes também partilham um certo marxismo heterodoxo, pois viam o colonialismo não como um confronto exclusivo entre classes mas como um confronto entre povos e entre colonizado e colonizador - a opressão não era só uma exploração económica exercida por uma classe social contra a outra mas uma opressão exercida também nos planos político, social, cultural, etc. (Samson, 2014: 6) -, tendo por isso inovado e renovado os estudos marxistas e os próprios estudos sobre o colonialismo. Isso não invalida que fizessem uma análise dentro do quadro teórico marxista, com a crítica ao capitalismo, ao imperialismo, ao tipo de classes existentes em cada nação, à relevância da revolução e do socialismo, etc. Ora, as escolhas de António Melo e de José Rosa sinalizam também, por esta via, aquilo que foi uma postura relativamente mais heterodoxa do grupo de exilados de Bruxelas do qual faziam parte 
face ao perfil dominante na resistência, que na diáspora portuguesa foi durante algum tempo muito marcado pelo Partido Comunista Português (PCP), mais alinhado com o marxismo ortodoxo. Por seu lado, Leonel Cosme não alinhou com a perspectiva artísticocívica mais crítica, a dos nacionalistas africanos concentrados na revista Mensagem (da Casa dos Estudantes do Império), organização que tinha muitos elos de contacto com o PCP. Ao invés, procurou acolher uma grande diversidade de autores e de estéticas no projecto editorial que animou, o qual foi exposto em textos programáticos ambíguos como recurso para também (mas não só) escapar o máximo de tempo possível à censura $\mathrm{e}$ à repressão políticas.

Em quinto lugar, Memmi e Fanon partilham ainda um lugar relevante na formação do pensamento teórico da descolonização. Esse legado está patente na abordagem do colonialismo enquanto confronto entre povos (mencionada acima) numa perspectiva de longa duração e tendo em conta as várias dimensões da acção humana (política, económica, social, cultural). Propunham um humanismo distinto do anterior (imposto pelas potências coloniais), que reputavam falso por se ficar pelo enunciado da igualdade de tratamento. Fanon revelou-se mais distanciado do que Memmi no tipo de humanismo teorizado, de novo cunho, mais dialéctico e, de par, mais radical, implicando uma ruptura absoluta com todo o legado colonial e, em última instância, com o sistema capitalista, conferindo um lugar central à questão da violência política, no âmago tanto do sistema colonial como da libertação dos povos colonizados ou já pós-coloniais (Crowley, 2012), embora não sendo por si desejada ou inamovível, antes resultando das lutas de independência e de "regressões identitárias e étnicas" (Mata, 2015). Para Fanon, a solução para o futuro dos novos povos teria de passar pela adopção dum socialismo internacionalista; ou seja, este vingaria se fosse feito em cada nação e em articulação com as nações afins, pois só deste modo se podia romper com a relação de forças existente a nível internacional, onde o capitalismo dominava.

Em sexto lugar, nota-se um mesmo gosto pelas obras e autores censurados, proibidos e/ou perseguidos, bem como pelos circuitos clandestinos e familiares (aquisições de livros no estrangeiro sem serem declarados publicamente na alfândega; criação de circuitos alternativos de difusão de obras, etc.).

Por fim, cabe realçar que os conteúdos escolhidos pelos depoentes - espelho dos gostos e opções duma geração letrada e politizada - foram elaborados, reelaborados e circularam em diferentes suportes, formas, datas, edições, línguas e países (sendo o caso mais emblemático a génese e evolução de Retrato do colonizado precedido do retrato do colonizador, de Albert Memmi), demonstrando a sua influência intelectual e sociológica, isto apesar das várias censuras políticas que lhes foram movidas. Os inúmeros paratextos, estudos e reedições que lhes respeitam evidenciam a sua actualidade e relevância enquanto fontes de referência e análise crítica.

\section{BIBLIOGRAFIA}

ALMEIDA, João Miguel (2008), A oposição católica ao Estado Novo, 1958-1974, Lisboa, Nelson de Matos. 
ANTUNES, Maria José Lobo (2015), Regressos quase perfeitos, Lisboa, Edições Tinta da China.

ANÓNIMO (1970), “Écrit sur l'écorce du coeur" (poemas por Gaston-Henry Aufrère)”, magazine Tempo, n.․15, 27 de Dezembro, edição de Tempográfica, p. 65, <http://www.aluka.org/action/ showMetadata?doi=10.5555/AL.SFF.DOCUMENT.ahmtem19701227>.

ARANTES, Marco Antonio (2011), "Sartre e o humanismo racista europeu: uma leitura sartriana de Frantz Fanon”, Sociologias, Porto Alegre, n. 27, pp. 382-409.

ASHCROFT, Bill; GRIFFITHS, Gareth; TIFFIN, Helen (2006), The Post-colonial Studies Reader, Nova Iorque, Oxford.

BONN, Charles ([1999]), “Articles sur l'oeuvre d'Albert Memmi”, Limag, CICLIM - Coordination Internationale des Chercheurs sur les Littératures du Maghreb, <http://www.limag.refer.org/ Volumes/ArticlesSurMemmi.htm>.

CABEÇADAS, Helena (2014), Bruxelas, Lisboa, Chiado Editores.

CARDINA, Miguel (2009), “Guerra à guerra. Violência e anticolonialismo nas oposições ao Estado Novo", oficina do CES, n.․ 334, Coimbra, CES-UC, <https://www.ces.uc.pt/myces/UserFiles/ livros/353_334.pdf>.

CARDINA, Miguel (2013), "Violência, testemunho e sociedade. Incómodos e silêncios em torno da memória da ditadura”, in Maria Paula Meneses e Bruno Sena Martins (org.), As guerras de libertação e os sonhos coloniais, Coimbra, Edições Almedina, pp. 29-39.

CELLIER, Patrick Le (2012), "Hara-Kiri/Charlie-Hebdo: Cavanna, Cabu et les autres vus de 1974", Mediapart, 13 de Junho, <http://blogs.mediapart.fr/blog/patrick-le-cellier/130612/hara-kiricharlie-hebdo-cavanna-cabu-et-les-autres-vus-de-1974>.

CONSTANT, Marie-Hélène (2014), "Dévider Albert Memmi: Paul Chamberland et son portrait du colonisé québécois (Parti pris, nos 9-10-11, été 1964)", Postures, dossier “Corps et nation: frontières, mutation, transfert", n.․ 20, pp. 115-125, <http://revuepostures.com/fr/articles/ constant-20>.

COSME, Leonel (2004), Agostinho Neto e o seu tempo, Porto, Campo das Letras.

COSME, Leonel (2015), "Recordar é viver (no cinquentenário do livro Luuanda de Luandino Vieira)", blogue Jardim das Delícias, 27/1, <http://jardimdasdelicias.blogs.sapo.pt/recordar-eviver-no-cinquentenario-do-713815>.

CROWLEY, Patrick (2012), “Memmi and Béji: Decolonization and the place of the 'human' within 'humanism”', International Journal of Francophone Studies, vol. 15, n. 3\&4, pp. 415-433, <doi: 10.1386/ijfs.15.3\&4.415_1>.

CUNHA, O. M. G. da (2002), "Reflexões sobre biopoder e pós-colonialismo: relendo Fanon e Foucault”, Mana, Rio de Janeiro, vol. 8, n.. 1, pp. 149-164.

DUGAS, Guy (2011), “Albert Memmi: Portrait du colonisé, précédé d'un Portrait du colonisateur. Note sur une postface autographe inédite", Genesis, n. 33, pp. 119-126, <http://genesis.revues.org/621 $>$.

FANON, Frantz (2011), OEuvres, Paris, La Découverte, prefácios de Achille Mbembe, Francis Jeanson e Sartre, introd. Magali Bessone e posf. Francis Jeanson.

FERRÃO, Manuela; OLIVEIRA, Susana; FONSECA, Teresa (org.) (2005), Livros proibidos no Estado Novo , Lisboa, Assembleia da República. 
FERREIRA, Nuno Estêvão (1994), “O Tempo e o Modo. Revista de Pensamento e Acção (1963-1967): repercussões eclesiológicas de uma cultura de diálogo”, Lusitania Sacra: Revista do Centro de Estudos de História Religiosa, n.ำ 4, pp. 129-294.

FERREIRA, Nuno Estêvão (2000), “Os meios católicos perante a guerra colonial: reconfigurações da questão religiosa em Portugal”, Lusitania Sacra, n.․12, pp. 221-266.

FRANK, Robert (1992), “La mémoire et l'histoire”, Les Cahiers de l'IHTP, n.o 21 (dossier “La Bouche de la vérité? La recherche historique et les sources orales”, dir. Danièle Voldman), pp. 65-72.

GAY, Paul du; EVANS, Jessica; REDMAN, Peter (2006), Identity: a reader, Londres e Nova Deli, Thousand Oaks.

GEARHART, Suzanne (1998), "Colonialism, psychoanalysis and cultural criticism: the problema of interiorization in the work of Albert Memmi", in John Carlos Rowe (ed.), "Culture" and the Problem of the Disciplines, Nova Iorque, Columbia University Press, pp. 171-197.

GOMES, Catarina (2015), “Cada soldado tem a sua guerra”, Público, 18 de Outubro, pp. 9-11 (sup. "Revista 2"), <http://www.publico.pt/portugal/noticia/cada-soldado-tem-a-suaguerra-1711282 >. HOLDT, Karl von (2013). "The violence of order, orders of violence: Between Fannon and Bourdieu”, Current Sociology, vol. 61, n.․ㅡ 2 (n.․especial: "Violence and Society"), pp. 112-131, <doi: $10.1177 / 0011392112456492>$.

LEAL, José Bação (2015 [1971]), Poesias e cartas, Lisboa, Público.

LOFF, Manuel; PIEDADE, Filipe; SOUTELO, Luciana Castro (eds.) (2014), Ditaduras e Revolução. Democracia e políticas da memória, Coimbra, Almedina.

MARTINS, Bruno Sena (2015), "Violência colonial e testemunho: para uma memória pós-abissal", Revista Crítica de Ciências Sociais, n.․ 106, pp. 105-126, <http://rccs.revues.org/5904>.

MATA, Inocência (2015), “Prefácio”, in Frantz Fanon, Os condenados da terra, Lisboa, Letra Livre, < http://www.buala.org/pt/mukanda/a-pertinencia-de-se-ler-fanon-hoje-parte-1>.

MELO, António; CARMO, Isabel do (coord.; 2001), Conversas de Inverno: os testemunhos de cinco protagonistas do século XX português: Emídio Guerreiro, Dinis Machado, Ludgero Pinto Basto, Ângela Vidal, Edmundo Pedro, Lisboa, Ler Devagar.

MELO, Daniel (2009), "Portugalidade e regionalidade no associativismo migrante português: o caso da Bélgica", in Daniel Melo e Eduardo Caetano da Silva (orgs.), Construção da nação e associativismo na emigração portuguesa, Lisboa, Imprensa de Ciências Sociais, pp. 193-235.

MELO, Daniel (2013), "Entre as brumas de Londres: literatura e mundo no exílio português", Colóquio/Letras, n.․1ㄹ, ISSN 0010-1451, pp. 25-35.

MEMMI, Albert (1965), “Interview”, Croissance des jeunes nations, Paris, ISSN 0011-1686, n. 44, Maio.

MUNGAZI, Dickson A. (1986), “Application of Memmi's Theory of the Colonizer and the Colonized to the Conflicts in Zimbabwe", The Journal of Negro Education, vol. 55, n. 4, pp. 518-534, <http:// www.jstor.org/stable/2294835>.

MUZZIO, Henrique (2013), "Persistência do colonialismo: primavera árabe compreendida além de seu tempo“, Revista de Administração de Empresas, vol. 53, n.. 1, pp. 92-93, <www.scielo.br/pdf/rae/ v53n1/v53n1a09.pdf>.

PCM. Comissão do Livro Negro sobre o Regime Fascista (1981), Livros proibidos no regime fascista, Mem Martins, Comissão do Livro Negro sobre o Regime Fascista. 
PINTO, António Costa (2001), o fim do Império português, Lisboa, Livros Horizonte.

PINTO, José Filipe (2011), Segredos do Império da Ilusitânia: a censura na Metrópole e em Angola, Coimbra, Almedina.

PORTAS, Catarina (2008), “O último livro da Ulisseia s.f.f.”, Público (sup. Ípsilon), 1 de Dezembro, <http://ipsilon.publico.pt/livros/texto.aspx?id=217736>.

SANCHES, Manuela Ribeiro (org.) (2011), Malhas que os impérios tecem: textos anticoloniais, contextos pós-coloniais, Lisboa, Edições 70.

SANSON, Hervé (2014), "En amont du Portrait du colonisé d'Albert Memmi: aux sources d'une pensée de la décolonisation", Continents manuscrits, n.ำ 1 (2014), pp. 2-23, <http:// coma.revues.org/231>.

SANTOS, Donizeth Aparecido dos (2007), "Da ruptura à consolidação: um esboço do percurso literário angolano de 1948 a 1975”, Publicatio UEPG Ciências Humanas, Linguística, Letras e Artes, vol. 15, n. ${ }^{\circ}$ 1, pp. 31-42, <http://www.revistas2.uepg.br/index.php/humanas/article/ viewFile/574/573>.

SIMÕES, Rui (2012), Guerra ou paz, Lisboa, Realficção, filme documentário.

SLOVAR (2008), "Philippe VAL ou la deuxième mort de Charlie Hebdo", Bella Ciao, 24 de Julho, < http://bellaciao.org/fr/spip.php?article69396>.

VAINFAS, Ronaldo (2008), "Albert Memmi: Retrato do colonizado precedido do retrato do colonizador”, Folha de São Paulo, p. 9. Caderno Mais!, 6 de Janeiro, <http:// www1.folha.uol.com.br/fsp/mais/fs0601200817.htm>.

WILLIAMS, Patrick; CHRISMAN, Laura (1993), Colonial Discourse and Post-colonial Theory: a reader, Harlow (Essex), Prentice Hall.

WINOCK, Michel (2000 [1999]), O século dos intelectuais, Lisboa, Terramar.

YPERSELE, Laurence van (2006), Questions d'Histoire contemporaine. Conflits, mémoires et identités, Paris, PUF.

\section{ANEXOS}

\section{Apresentação da tertúlia (material integrante do convite e do cartaz de divulgação) Um livro, uma revista, uma canção contra a Guerra Colonial}

Esta tertúlia pretende ser uma iniciativa original de apresentação de testemunhos contra a Guerra Colonial (1961-74), e contra a guerra em geral, partindo da escolha pessoal de um livro, uma revista e/ou uma canção que tenham sido marcantes nessa tomada de consciência cívica. Várias destas escolhas foram então censuradas, em Portugal, França, etc. 
A uma parte inicial de depoimento, acompanhada por divulgação de imagens (em projecção ou impressas) e reprodução da canção escolhida, segue-se um período de debate que se pretende vivo e aberto. Pretende-se assim contribuir para um conhecimento mais aprofundado dos tempos e modos de circulação de conteúdos culturais que alimentaram o ideário progressista e a resistência. Uma resistência que se construíra a nível mundial: contra as outras guerras que então ecoavam (da Guerra Fria ao Vietname e a Cuba), contra a opressão colonialista e as ditaduras. Buscou-se desse modo romper com fronteiras criadas em nome da nação: os nacionalismos belicistas; o colonizador vs. o colonizado. Uma das inovações que se busca é a de dar voz a grupos de exilados cujo legado foi abafado pela censura, pela distância, pelo olvido e pelo perfil de memória pública que se afirmou em Portugal, no decurso dos 40 anos que nos separam do fim dessa guerra.

Anexo

\section{Canção escolhida para a sessão 2 - "Le Déserteur" (inclui o poema homónimo e ainda o poema "Le Dormeur du val")}

Nota: "Le Déserteur", na versão interpretada por Serge Reggiani, 1964 (contendo dois poemas a seguir transcritos nas versões original e em língua portuguesa: o poema homónimo de Boris Vian e música de Boris Vian e Harold Berg, 1954, com tradução para português de António Melo; antecedido pelo poema "Le Dormeur du val", de Rimbaud, 1870, com tradução para português de Ivo Barroso).

Le dormeur du val

C'est un trou de verdure où chante une rivière Accrochant follement aux herbes des haillons D'argent; où le soleil, de la montagne fière, Luit: c'est un petit val qui mousse de rayons. Un soldat jeune, bouche ouverte, tête nue, Et la nuque baignant dans le frais cresson bleu, Dort; il est étendu dans l'herbe, sous la nue, Pâle dans son lit vert où la lumière pleut. Les pieds dans les glaïeuls, il dort. Souriant comme Sourirait un enfant malade, il fait un somme: Nature, berce-le chaudement: il a froid. Les parfums ne font pas frissonner sa narine; Il dort dans le soleil, la main sur sa poitrine Tranquille. Il a deux trous rouges au côté droit. Rimbaud

0 adormecido do vale

Era um recanto onde um regato canta Doidamente a enredar nas ervas seus pendões De prata; e onde o sol, no monte que suplanta, Brilha: um pequeno vale a espumejar clarões. Jovem soldado, boca aberta, fronte ao vento, $E$ a refrescar a nuca entre os agriões azuis, Dorme; estendido sobre as relvas, ao relento, Branco em seu leito verde onde chovia luz. Os pés nos juncos, dorme. E sorri no abandono 
De uma criança que risse, enferma, no seu sono:

Tem frio, ó Natureza - aquece-o no teu leito.

Os perfumes não mais lhe fremem as narinas;

Dorme ao sol, suas mãos a repousar supinas

Sobre o corpo. E tem dois furos rubros no peito.

Tradução de Ivo Barroso

Le déserteur

Monsieur le Président

Je vous fais une lettre

Que vous lirez peut-être

Si vous avez le temps

Je viens de recevoir

Mes papiers militaires

Pour partir à la guerre

Avant mercredi soir

Monsieur le Président

Je ne veux pas la faire

Je ne suis pas sur terre

Pour tuer des pauvres gens

C'est pas pour vous fâcher

Il faut que je vous dise

Ma décision est prise

Je m'en vais déserter

Depuis que je suis né

J'ai vu mourir mon père

J'ai vu partir mes frères

Et pleurer mes enfants

Ma mère a tant souffert

Elle est dedans sa tombe

Et se moque des bombes

Et se moque des vers

Quand j'étais prisonnier

On m'a volé ma femme

On m'a volé mon âme

Et tout mon cher passé

Demain de bon matin

Je fermerai ma porte

Au nez des années mortes

J'irai sur les chemins

Je mendierai ma vie

Sur les routes de France

De Bretagne en Provence

Et je dirai aux gens:

Refusez d'obéir

Refusez de la faire

N'allez pas à la guerre

Refusez de partir

S'il faut donner son sang

Allez donner le vôtre

Vous êtes bon apôtre

Monsieur le Président

Si vous me poursuivez

Prévenez vos gendarmes

Que je n'aurai pas d'armes

Et qu'ils pourront tirer

Boris Vian 


\section{O desertor}

Senhor Presidente

Aqui lhe envio uma carta

Que talvez leia

Se para isso tiver tempo

Acabo de receber

A convocatória militar

Para seguir para a guerra

Antes de quarta-feira

Senhor Presidente

Não quero ir

Não vim a esta terra

Para matar a pobre gente

Não é para o zangar

Mas tenho de o dizer

Já tomei a minha decisão

Vou desertar

Desde que nasci

Vi morrer o meu pai

Vi partir os meus irmãos

E chorar os meus filhos

Tanto sofreu a minha mãe

Encerrada no seu túmulo

Quer lá saber das bombas

E troça da bicharada

Quando estive prisioneiro

Roubaram-me a mulher

Roubaram-me a alma

E todo o meu doce passado

Amanhã bem cedo

Fecharei a porta

$\mathrm{Na}$ cara destes anos mortos

Vou por aí

Mendigarei a minha vida

Pelas estradas de França

Da Bretanha à Provença

$E$ vou dizer às pessoas:

Recusem obedecer

Recusem-na

Não vão à guerra

Recusem partir

Se é preciso verter o sangue

Dai o vosso

Bom apóstolo que sois

Senhor Presidente

Se me perseguir

Preveni os polícias

Que não estarei armado

E que podem disparar

Tradução de António Melo

\section{NOTAS}

1. Quanto aos militares, uma recente pesquisa académica de Maria José Lobo Antunes realça esse mesmo facto: "Eles [os ex-combatentes do batalhão do seu pai] voltaram a 1 de Março 1973, um 
ano depois deu-se o 25 de Abril, e em 1975 a descolonização. Houve uma aceleração do processo histórico nos anos a seguir e o Estado Novo e a guerra tornaram-se um imenso silêncio, uma zona de incómodo que era difícil de gerir. Esta é uma parte da resposta. Só com o distanciamento que o tempo traz se começoulentamente a voltar a falar da guerra. As condições "“da possibilidade da memória" alteraram-se" (Gomes, 2015). Mesmo esta é uma rememoração que evacua boa parte desse passado, e que raramente interpela a guerra criticamente: "Os almoços [de convívio entre os ex-combatentes] são o lado solar e luminoso de uma experiência tão violenta como é a guerra. Desaparece tudo o que possa criar desacordo, agora que são homens de 60 anos, questões como 'qual o sentido da guerra', 'a legitimidade da presença portuguesa em África', 'África e os seus habitantes'. Nada disso é falado. É deixado de fora.” Esta interpretação baseia-se na sua tese de doutoramento (vd. Antunes, 2015). Do lado dos desertores e exilados, há um forte pendor crítico, mas a configuração da "memória pública" (mormente da "memória oficial") nos últimos 40 anos foi no sentido de limitar a visibilidade desse olhar, ou, genericamente, dum olhar crítico do legado ditatorial (v.g., Cardina, 2013; Loff, Piedade \& Soutelo, ed., 2014; Martins, 2015). A própria autobiografia específica é recente e pouco visível (v.g., Melo, 2013). Sobre os conceitos de “memória pública" e de "memória oficial", vd. Frank, 1992: 69; Ypersele, 2006: 195-196.

2. Para uma definição sistematizada de memória colectiva e uma apologia da historicização crítica das práticas de memória e dos seus efeitos sobre as colectividades (incluindo os abusos cometidos em nome da memória), vd. Ypersele, 2006: 191-201. Para um enquadramento da Guerra Colonial portuguesa e sua relevância em termos políticos, económicos e sociais, incluindo uma perspectiva comparada com outras guerras marcantes do século XX, vd. Pinto, 2001.

3. Apesar de os livros mencionarem serem edição dos próprios autores, o que era uma forma de protecção da empresa, como refere Cosme no seu depoimento.

4. Cf. Cosme, 2004: 141-66 e 2015; Santos, 2007; Pinto, 2011: 123 (este último sem referência à PIDE). Em Cosme, 2015 e no seu depoimento que aqui publicamos, refere-se ainda que a incursão da PIDE à livraria Imbondeiro serviu também para apreender os exemplares sobrantes do livro Grandes poetas do século XX, livro "internacionalista" que publicou autores pacifistas como o francês Gaston-Henry Aufrère (vd. magazine Tempo, n.. 15, 1970, p. 65) ou proibidos como o húngaro Attila Jozsef, o alemão Bertolt Brecht, o grego Elias Simopoulos, o romeno Eugen Jebeleanu, o checoslovaco Jirí Wolker, o norte-americano Langston Hughes, o chileno Pablo Neruda, o espanhol Rafael Alberti, o inglês T. S. Eliot e o soviético Vladimir Maiakovski, entre outros.

5. Cf. perfil do autor em <http://www.wook.pt/authors/detail/id/4671> e notas sobre o último romance da pentalogia, 0 chão das raízes, em <http://www.unicepe.pt/jantares/ jantares/101_jantar/101_jantar.html>.

6. Sobre a oposição anti-salazarista e seu posicionamento relativamente à Guerra Colonial, vd. Cardina, 2009. Sobre os católicos progressistas, vd. Ferreira, 1994 e 2000; Almeida, 2008.

7. Vd. Melo, 2009: máxime 196-197; Simões, 2012; Cabeçadas, 2014.

8. A primeira versão em língua portuguesa editada em Portugal é Retrato do colonizado precedido do retrato do colonizador, Lisboa, Mondar Editores, Julho de 1974. Este livro foi impresso na tipografia Editorial Império (cf. http://pt.wikipedia.org/wiki/MONDAR_editores).

9. Memmi foi ensaiando o tema em conferências e em crónicas que saíram na imprensa, ambas em 1956. Logo depois publicou um texto mais longo, intitulado "Portrait du colonisateur de bonne volonté", na revista Les Temps modernes, n.o de Abril de 1957. De seguida, saiu o texto "Portrait du colonisé précédé du portrait du colonisateur", na revista Esprit, em Maio de 1957, o qual complementava e corrigia o anterior. Em Junho do mesmo ano sai em Paris a primeira versão em livro, por Buchet/Chastel \& Corrêa. Sobre a génese e evolução desta obra, vd. Dugas, 2012. Sobre a evolução da posição do autor e a génese do seu pensamento anticolonial, vd. Sanson, 2014.

10. Sobre o lugar de Sartre, vd. Winock, 2000. 
11. Ilação minha após confronto de diversas versões feitas em França, Brasil e Portugal. Enquanto prefácio só surgirá em livro após as independências, primeiramente na edição de Pauvert (Paris, Jean-Jacques Pauvert, colecção "Libertés" n. 37, 1966, in-12, brochado, 184 p.). A versão da Payot, de 1973, está disponível em linha (em http://fr.slideshare.net/anattaembe/memmi-portrait-ducolonis). Sobre a evolução dos paratextos desta obra, cf. Dugas, 2012: 119 e 126.

12. Veja-se o seu uso pelo nacionalismo do Quebeque (Constant, 2014).

13. Além de Sartre e de vários teóricos independentistas africanos, vd. Mungazi, 1986 e Gearhart, 1998. Para todos, vd. ainda a extensa lista bibliográfica elaborada por Bonn, 1999.

14. Além das referidas atrás, vd. também as edições em inglês da Beacon Press (Boston, 1965), em português da Paz e Terra (Rio de Janeiro, 1967, série "Ecumenismo e humanismo", n.o 11) e em francês da Gallimard (Paris, 1985).

15. The Colonizer and the Colonized, Londres, Earthscan, trad. Howard Greenfeld, introd. Jean-Paul Sartre, nova introd. Nadine Gordimer, 2003, $198 \mathrm{pp}$.

16. Iniciativa assumida pelo próprio em recente entrevista (vd. <http:// ofuncionariocansado.blogspot.pt/2007_07_01_archive.html>). Aproveita-se para deixar hiperligações para o respectivo texto integral das primeiras edições em Portugal (<https:// www.marxists.org/portugues/fanon/1961/condenados/index.htm>) e no Brasil, esta da Civilização Brasileira, Rio de Janeiro, 1968 (<https://www.google.pt/url? $\mathrm{sa}=\mathrm{t} \& \mathrm{rct}=\mathrm{j} \& \mathrm{q}=\& \mathrm{esrc}=\mathrm{s} \&$ source=web\&cd=2\&cad=rja\&uact=8\&ved=0CCAQFjABahUKEwik6JHqpJ7IAhXDbRQKHSKWCWM\&url=https \%3A\%2F\%2Fdocs.google.com\%2Fopen\%3Fid\% 3D0B2_ZKqR9WEKRmV4N01seGs2MTA\&usg=AFQjCNER219cFk9uJ4NUGFLo2CBr43fkNA>).

17. Cf. Portas, 2008. Esta ideia foi-me também transmitida por um livreiro antiquário com loja no Chiado durante décadas, Luiz Gomes.

18. Vd. fac-simile do ofício n. $3794-\mathrm{CI}(2)$ da Secção Central da PIDE para o Inspector da PIDE em Coimbra, de 17/10/1967, com anotação manuscrita de apreensão do livro em apreço via circular confidencial 1784 de 9/4/1965 (cf. Ferrão, Oliveira e Fonseca, 2005: 91). Aquele ofício tem o título mal grafado ("Los condenados da terra"), podendo querer referir-se à edição mexicana, Los condenados de la tierra, México, Fondo de Cultura Económica, 1963. Porém, é improvável, pois a edição da Ulisseia consta da lista oficial de livros censurados (cf. PCM. Comissão do Livro Negro sobre o Regime Fascista, 1981: 38). Este livro também foi lido e recomendado pelo poeta-soldado José Bação Leal a um amigo, no final de 1962, pouco antes de morrer, em Angola, já em plena Guerra Colonial (cf. Leal, 2015).

19. Desde os estudos sobre identidade e psicanálise (v.g., Gay, Evans \& Redman, 2006) aos estudos pós-coloniais (v.g., Williams \& Chrisman, 1993; Cunha, 2002; Ashcroft, Griffiths \& Tiffin, 2006; Arantes, 2011; Sanches, 2011), passando pelo repensar da violência junto com Bourdieu (Holdt, 2013) e pelas opus omnia com paratextos de revisitação crítica (Fanon, 2011). Para mais estudos, vd. série "La pensée de Frantz Fanon à l'épreuve du temps" (<http://frantzfanonfoundationfondationfrantzfanon.com/>), <http://data.bnf.fr/12016577/frantz_fanon/studies> e <https:// en.wikipedia.org/wiki/Frantz_Fanon>.

20. Para uma história desta revista de culto, e alusão a estudos académicos específicos, vd. Cellier, 2011.

21. Vd. ibidem; para a interdição nas casernas, vd. Slovar, 2008.

22. As quais podem ser escutadas em <http://secondhandsongs.com/work/56270/versions\#naventity>. 


\section{AUTOR}

\section{DANIEL MELO}

CHAM, FCSH, Universidade NOVA de Lisboa, Universidade dos Açores, Portugal.

daniel.melo@fcsh.unl.pt

Investigador integrado e vicecoordenador do grupo de investigação «Leitura e formas da escrita» do CHAM, Faculdade de Ciências Sociais e Humanas, Universidade NOVA de Lisboa, Universidade dos Açores. Doutor em História Moderna e Contemporânea pelo ISCTE - Instituto Universitário de Lisboa, Prémio de História Contemporânea Victor de Sá para a sua tese de doutoramento A leitura pública no Portugal contemporâneo (ICS, 2004). Entre os seus últimos trabalhos constam o capítulo do livro "A cultura" (in História contemporânea de Portugal, 1808-2010, Lisboa, Objetiva, vol. 4 , 2015) e o livro História e património da edição - A Romano Torres (Lisboa e Famalicão, CHAM e Húmus, 2015). Coordena um projecto de pesquisa sobre a circulação e recepção do impresso no espaço iberoamericano, sendo bolseiro de pós-doutoramento da Fundação para a Ciência e a Tecnologia (SFRH/BPD/104105/2014). CV breve em http://unl-pt.academia.edu/DanielMelo. He is a Research fellow and vice-coordinator of the Research Group «Reading and the forms of writing» at the Portuguese Centre for Global History (CHAM, Faculdade de Ciências Sociais e Humanas, Universidade NOVA de Lisboa, Universidade dos Açores). His PhD thesis, A leitura pública no Portugal contemporâneo (1926-1987) [Public Reading in contemporary Portugal (1926-1987)], received the Victor de Sá Contemporary History Prize and was published by Imprensa de Ciências Sociais in 2004. Among his latest works are the book chapter "A cultura" [Culture] (in História contemporânea de Portugal, 1808-2010, Lisbon, Objetiva, vol. 4, 2015) and the book História e património da edição - A Romano Torres [Publishing History and Heritage - The Romano Torres publishing house] (Lisbon and Famalicão, CHAM e Húmus, 2015). He is currently working on a post-doctoral research project about the circulation and reception of printed matter and ideas in IberoAmerica, funded by the Fundação para a Ciência e a Tecnologia (SFRH/BPD/104105/2014). Brief CV at http://unl-pt.academia.edu/DanielMelo. 